\title{
Immunoregulatory mechanisms in Chagas disease: modulation of apoptosis in T-cell mediated immune responses
}

\author{
Ana Thereza Chaves ${ }^{1}$, Juliana de Assis Silva Gomes Estanislau ${ }^{1,2,3}$, Jacqueline Araújo Fiuza', \\ Andréa Teixeira Carvalho ${ }^{4}$, Karine Silvestre Ferreira ${ }^{2}$, Rafaelle Christine Gomes Fares ${ }^{1}$, \\ Pedro Henrique Gazzinelli Guimarães ${ }^{5}$, Elaine Maria de Souza Fagundes ${ }^{6}$, Maria José Morato ${ }^{1}$, \\ Ricardo Toshio Fujiwara ${ }^{5}$, Manoel Otávio da Costa Rocha ${ }^{3}$ and Rodrigo Correa-Oliveira ${ }^{1,7,8^{*}}$
}

\begin{abstract}
Background: Chronic Chagas disease presents different clinical manifestations ranging from asymptomatic (namely indeterminate) to severe cardiac and/or digestive. Previous results have shown that the immune response plays an important role, although no all mechanisms are understood. Immunoregulatory mechanisms such as apoptosis are important for the control of Chagas disease, possibly affecting the morbidity in chronic clinical forms. Apoptosis has been suggested to be an important mechanism of cellular response during T. cruzi infection. We aimed to further understand the putative role of apoptosis in Chagas disease and its relation to the clinical forms of the disease.

Methods: Apoptosis of lymphocytes, under antigenic stimuli (soluble T. cruzi antigens - TcAg) where compared to that of non-stimulated cells. Apoptosis was evaluated using the expression of annexin and caspase $3^{+}$by $T$ cells and the percentage of cells positive evaluated by flow cytometry. In addition activation and T cell markers were used for the identification of TCD4 ${ }^{+}$and $\mathrm{TCD}^{+}$subpopulations. The presence of intracellular and plasma cytokines were also evaluated. Analysis of the activation status of the peripheral blood cells showed that patients with Chagas disease presented higher levels of activation determined by the expression of activation markers, after TcAg stimulation. PCR array were used to evaluate the contribution of this mechanism in specific cell populations from patients with different clinical forms of human Chagas disease.
\end{abstract}

Results: Our results showed a reduced proliferative response associated a high expression of $\mathrm{T} \mathrm{CD4}{ }^{+} \mathrm{CD}_{2} 2 \mathrm{~L}^{-}$cells in CARD patients when compared with IND group and NI individuals. We also observed that both groups of patients presented a significant increase of $\mathrm{CD}^{+}$and $\mathrm{CD} 8^{+} \mathrm{T}$ cell subsets in undergoing apoptosis after in vitro stimulation with $T$. cruzi antigens. In CARD patients, both $\mathrm{CD}^{+}$and $\mathrm{CD} 8^{+} \mathrm{T}$ cells expressing TNF-a were highly susceptible to undergo apoptosis after in vitro stimulation. Interestingly, the in vitro TcAg stimulation increased considerably the expression of cell death TNF/TNFR superfamily and Caspase family receptors genes in CARD patients.

Conclusions: Taken together, our results suggest that apoptosis may be an important mechanism for the control of morbidity in T. cruzi infection by modulating the expression of apoptosis genes, the cytokine environment and/ or killing of effector cells.

Keywords: Chagas disease, Immunoregulation, Apoptosis, TNF/TNFR superfamily, Caspase family, T lymphocytes, Trypanosoma cruzi

\footnotetext{
* Correspondence: correa@cpqrr.fiocruz.br

'Laboratório de Imunologia Celular e Molecular, Centro de Pesquisas René

Rachou, Fiocruz, Belo Horizonte, Brazil

${ }^{7}$ Instituto Nacional de Ciência e Tecnologia em Doenças Tropicais - INCT-DT,

Minas Gerais, Brazil

Full list of author information is available at the end of the article
} 


\section{Background}

Chagas disease, a neglected disease caused by Trypanosoma cruzi, remains a serious public health problem and affects about 10 million people in Latin America [1]. Chronic cardiomyopathy represents the most important and severe manifestation of human Chagas disease, eventually affecting approximately 20-30\% of individuals. The majority of the chronically affected individuals present the indeterminate (IND) form of the disease, with an apparent absence of morbidity [2, 3]. Epidemiological studies in endemic areas have shown that 2-5\% of patients will evolve each year from the indeterminate to the cardiac clinical form of the disease [4].

Although the pathophysiology of Chagas disease is not completely understood, it is widely accepted that the involvement of the immune response is critical in determining the disease outcome [5-8]. While the balance between inflammatory and anti-inflammatory cytokines produced by circulating cells in patients with IND form leans towards to an anti-inflammatory profile, patients with chagasic cardiomyopathy seem to display a predominantly inflammatory pattern $[6,9,10]$. The type of immune response induced in these individuals seems to be critical for the maintenance of a "healthy" balance between the parasite and the host [11]. In fact, several studies have demonstrated that immunoregulatory mechanisms are important for the control of infection, possibly affecting disease morbidity in chronic clinical forms [11, 12] such as T-cell suppression, polyclonal lymphocyte activation, and regulatory cytokines $[13,14]$. Infection with $T$. cruzi leads to polyclonal lymphocyte activation [15], which, by itself, promotes T-cell apoptosis [16, 17]. In addition, antigens released by $T$. cruzi, such as trans-sialidase and HSP70, induce lymphocyte apoptosis $[18,19]$. Therefore, it is possible that the parasite exploits host cell apoptosis to evade the immune response. Evidences also indicate that apoptosis plays a role in the resolution of inflammation [20].

In the present work, we evaluated the contribution of apoptosis in specific $\mathrm{T}$ cell populations on the development/maintenance of different clinical manifestations of human Chagas disease. Our findings demonstrated that in vitro stimulation with $T$. cruzi antigens induce lymphocyte apoptosis by continued cell activation, modulation of the expression of apoptosis genes and cytokine secretion profile. These findings may contribute to the regulation of immune response during human Chagas disease.

\section{Methods}

\section{Study population}

The patients that agreed to participate in this study were identified and selected from those being attended at the Referral Outpatient Center for Chagas Disease, which is located at the Clinics Hospital of the Federal University of Minas Gerais (UFMG), Brazil, under the medical care of one of us (MOCR). These patients were enrolled in a prospective cohort study initiated 20 years ago as previously described [13]. Patients infected with T. cruzi were grouped as indeterminate (IND) or with cardiomyopathy (CARD). The IND group included 15 asymptomatic individuals with age ranging from 24 to 66 years (mean of $39.6 \pm 10.3$ ), with no significant alterations in electrocardiography, chest X-ray and echocardiogram. The CARD group included 15 patients with age ranging from 23 to 69 years (mean of $48 \pm 12.52$ ) presenting dilated cardiomyopathy, characterized by the echocardiographic finding of a dilated left ventricle with impaired ventricular systolic function. Left ventricular ejection fraction (LVEF) and left ventricular diastolic diameter (LVDD) were used as clinical parameters of the ventricular function for Chagas disease patients, where LVEF $<55 \%$ and LVDD/ body surface area $\geq 31 \mathrm{~mm}$ were used to define Chagas disease dilated cardiomyopathy [3]. None of the patients had undergone chemotherapeutic treatment, nor been previously treated for T. cruzi infection. Healthy individuals with age ranging from 29 to 55 years [mean of $42.6 \pm$ 8.8), from a non-endemic area for Chagas disease with negative serological tests for the infection were included in the control group (non-infected NI).

\section{Ethics statement}

This study was carried out in full accordance with all international and Brazilian accepted guidelines and was approved by the Ethics Committee of the René Rachou Research Center - FIOCRUZ (14/2006 CEPSH-IRR) and UFMG protocol COEP-ETHIC 001/79). All enrolled patients gave written informed consent prior to the inclusion in the study.

\section{Trypanosoma cruzi soluble antigen preparations}

The CL strain of T. cruzi was used for antigenic preparation as described elsewhere [21]. After preparation, the protein concentration was determined, aliquoted and stored at $70{ }^{\circ} \mathrm{C}$ prior use.

\section{Short-term in vitro whole blood cultures with $T$. cruzi antigens}

Whole blood samples (final concentration of $1 \times 10^{6}$ cells $/ \mathrm{mL}$ ) were treated with staurosporine (Sigma, St. Louis, MO, USA) $(4 \mu \mathrm{M})$, soluble $T$. cruzi antigens (TcAg) $(25 \mu \mathrm{g} / \mathrm{mL}$ ) or untreated (stimulated with medium alone - RPMI 1640 supplemented with $1.6 \%$ L-glutamine, $3 \%$ antibiotic-antimycotic, $5 \%$ of $A B$ Rh-positive heat-inactivated normal human serum), and incubated for approximately $24 \mathrm{~h}$ at $37{ }^{\circ} \mathrm{C}$ in $5 \% \mathrm{CO}_{2}$. Following incubation, the cultures were treated with $220 \mu \mathrm{L}$ of EDTA at $20 \mathrm{mM}$ and maintained at room temperature for $15 \mathrm{~min}$ 
prior immunophenotypic staining for apoptosis assay, cell surface markers, and intracellular cytokine analysis.

\section{Cell preparation and proliferation assay}

PBMC from Chagas patients and healthy individuals were isolated by Ficolldiatriazoate density gradient centrifugation (LSM; Organon Teknica, Charlesnton, S.C.) as previously described (Gomes, 2003). The cells were washed in RPMI 1640 medium and cultured in flat-bottom 96-well plates (Nunc Brand Products). Proliferative responses were evaluated by incubating $2.5 \times 10^{5}$ cells/well for TcAg $(25 \mu \mathrm{g} / \mathrm{mL})$ or $1.5 \times 10^{5}$ cell/well for mitogen stimulation (PHA, $10 \mu \mathrm{g} / \mathrm{mL}$ ), respectively, in a final volume of $200 \mu \mathrm{L}$ of complete RPMI-1640. Incubation was carried out in a humidified $5 \% \mathrm{CO} 2$ incubator at $37{ }^{\circ} \mathrm{C}$ for 3 days for PHA-stimulated cultures and 6 days for antigen-stimulated cultures. Cells were pulsed for the last $6 \mathrm{~h}$ of incubation with $1 \mu \mathrm{Ci}$ of $\left[{ }^{3} \mathrm{H}\right]$ methyl thymidine (PerkinElmer LAS, Shelton, CT, USA), and harvested onto glass fiber filters (Printed Filtermat A, Wallac, Finland). Radioactive incorporation was determined by liquid scintillation spectrometry (MicroBeta JET, PerkinElmer Inc., USA).

\section{Analysis of apoptosis profile}

Short-term in vitro whole blood cultures were washed with $6 \mathrm{~mL}$ of FACS buffer (PBS supplemented with $0.5 \%$ bovine serum albumin-BSA and $0.1 \%$ sodium azide) by centrifugation at $600 \mathrm{xg}$ for $7 \mathrm{~min}$ at room temperature and resuspended in $5 \mathrm{~mL}$ of FACS buffer.

For the annexin $\mathrm{V}$ analysis, aliquots of $150 \mu \mathrm{L}$ were transferred to polystyrene tubes and incubated for $30 \mathrm{~min}$ at room temperature (RT) with $2 \mu \mathrm{L}$ of allophycocyanin (APC) - labeled anti-CD4 (RPA-T4) (BD Pharmingen) or anti-CD8 (RPA-T8) (BD Pharmingen) monoclonal antibodies. Following incubation, the red blood cells were lysed by the addition of $3 \mathrm{~mL}$ of FACS lysing solution (Becton Dickinson, CA, USA) for $10 \mathrm{~min}$, and cells washed with $2 \mathrm{~mL}$ of PBS by centrifugation at $600 \mathrm{xg}$ for $7 \mathrm{~min}$ at room temperature. The cells were resuspended in annexin $\mathrm{V}$ binding buffer $(0.1 \mathrm{M}$ Hepes $/ \mathrm{NaOH}$ ( $\mathrm{pH}$ 7.4) 1.4 $\mathrm{M} \mathrm{NaCl}, 25 \mathrm{mM} \mathrm{CaCl}$ - Biosciences, San Jose, CA), for working solution (1X), then incubated for $15 \mathrm{~min}$ at RT $\left(25^{\circ} \mathrm{C}\right)$ in the dark with $5 \mu \mathrm{L}$ annexin V-PE and $5 \mu \mathrm{L}$ 7AAD. The reaction was stopped by the addition of $100 \mu \mathrm{L}$ of $1 \mathrm{x}$ binding buffer for each tube.

For caspase- 3 analysis, aliquots of $150 \mu \mathrm{L}$ of whole blood cultures were transferred to polystyrene tubes and incubated for $30 \mathrm{~min}$ at room temperature with $2 \mu \mathrm{L}$ of fluorescein isothiocyanate (FITC)-labeled anti-CD45 (2D1) (BD Biosciences) and $2 \mu \mathrm{L}$ of peridinin chlorophyll-a protein (PerCP)-labeled anti-CD14 (M5E2) (BD Biosciences) monoclonal antibodies. The tubes were incubated in the dark for $10 \mathrm{~min}$ at RT. The cells were permeabilized in saponin buffer (0.5 \%) (Sigma) for $15 \mathrm{~min}$ at RT in the dark. Finally, the cells were incubated with PE-conjugated rabbit anti-active caspase-3 mAb (C92-605) (BD Pharmingem) using $20 \mu \mathrm{L} / 1 \times 10^{6}$ cells for $60 \mathrm{~min}$ at $\mathrm{RT}$ in the dark. Phenotypic analyses were performed by flow cytometry using a Becton Dickinson FACScalibur flow cytometer Analysis was performed on $7 \times 10^{4}$ lymphocytes (gated according to their forward and side scatter properties. The sample acquisition and data analysis were performed using CellQuest software (BD Biosciences, USA).

\section{Analysis of cell surface markers and intracytoplasmic cytokines}

Cultured cells were washed twice in PBS containing $1 \%$ BSA and stained with monoclonal antibodies specific for cell-surface markers. Antibodies to CD4 (RPA-T4), CD8 (RPA-T8) and CD62L (DREG-56) (all from BD Pharmingen) were used. The cells were then fixed in formaldehyde $(4 \%)$ and permeabilized in saponin buffer $(0.5 \%)$ (Sigma, USA) for $15 \mathrm{~min}$. Finally, the cells were incubated with anti-TNF- $\alpha$ (PE) (L293) (BD Biosciences) washed and ressuspended in FACS buffer prior acquisition in flow cytometer.

Phenotypic analyses were performed by flow cytometry using a Becton Dickinson FACScalibur flow cytometer, collecting data on $7 \times 10^{4}$ lymphocytes gated according to their forward and side scatter properties. The sample acquisition and data analysis were performed using CellQuest software (BD Biosciences, USA).

\section{Detection of plasmatic cytokine levels by Cytometric Bead Array (CBA)}

A cytometric beads array (CBA) immunoassay kit (BD Biosciences, USA) was used to measure cytokine levels (IFN- $\gamma$, TNF- $\alpha$, IL-2 and IL-10) in plasma as described in previous studies [6]. The data were acquired in a Becton Dickinson FACScalibur flow cytometer and analyzed using BD CBA software (BD Biosciences, USA). The results were expressed by mean intensity of fluorescence (MIF).

\section{Apoptotic pathways triggered by $T$. cruzi infection in different clinical forms of Chagas disease}

In order to determine putative apoptotic pathways triggered by $T$. cruzi infection, PBMC from infected patients IND $(n=2)$ and CARD $(n=2)$ were incubated only with culture medium- culture non-stimulated; or in the presence of antigen- culture stimulated with $\mathrm{TcAg}$ at a final concentration of $25 \mu \mathrm{g} / \mathrm{mL}$. After $18 \mathrm{~h}$ of incubation at $37{ }^{\circ} \mathrm{C}$ and $5 \% \mathrm{CO}_{2}$ air, cells were recovered and washed with PBS. Subsequently, cells were submitted to a total RNA extraction protocol using NucleoSpin ${ }^{\bullet}$ RNA II kit (Macherey-Nagel, Germany). The total RNA was quantified according to standard procedures using spectrophotometer 
(Thermo Scientific, USA) and evaluated in agarose gel to confirm its integrity [22]. The cDNAs were obtained with Superscript II kit (Invitrogen, USA) using 120 ng of total RNA, according to manufacturer's instructions. Afterwards, a RT-PCR reaction was performed using previously established constitutive human primers to confirm the cDNA synthesis.

The apoptotic transcripts were evaluated using a Human Apoptosis $\mathrm{RT}^{2}$ Profiler $^{\mathrm{ma}}$ PCR Array kit (SABiosciences, USA) in a qPCR machine (7500, Applied Biosystem, USA), according to manufacturer's instructions. Thirty one transcripts involved with pro-apoptotic activity were evaluated. Out of thirty one genes, twenty belong to TNF and TNF receptor superfamily, cell death domains and inductors of apoptosis; and eleven to the caspases family, which are also involved with pro-apoptotic activity. The qPCR data were analyzed by PCR Array Data Analysis Web Portal (SABiosciences, USA), and the results were expressed using the method of $2^{-\Delta \Delta C}$.

\section{Statistical analyses}

Statistical analyses were conducted using the R 2.15.0 software. Initially, the Anderson-Darling test was applied to verify whether the obtained data represent a normal distribution. Statistical comparative analyses were performed using the non-parametric: Mann-Whitney test to compare two groups (NI $x$ IND or NI $x$ CARD or IND $x$ CARD); Kruskal-Wallis test to compare three groups (NI $x$ IND $x$ CARD) and, together with the Bonferroni correction (significance level, $0.05 / 3=0.0167$ ). All tests were performed considering a significance level of $5 \%(\alpha=0.05)$.

\section{Results}

\section{Cellular proliferative response is decreased in CARD patients}

The proliferative immune response was analyzed in PBMC from IND and CARD patients as well as NI individuals stimulated with soluble T. cruzi antigens (TcAg) by the quantification of $\mathrm{H}^{3}$-thymidine incorporation. We observed that PBMC proliferative response of the IND group had a significantly higher $(p<0.05)$ level of cellular proliferation after stimulation with TcAg when compared with CARD and NI groups (Fig. 1). No significant difference was observed in the proliferative response induced by PHA (data not shown).

\section{Increased downregulation of CD62L in $\mathrm{CD}^{+} \mathrm{T}$ cells is related to CARD patients}

We also evaluated the loss of expression $\left(\mathrm{CD}^{2} 2 \mathrm{~L}^{-}\right)$in circulating $\mathrm{CD} 4^{+}$and $\mathrm{CD}^{+}{ }^{+} \mathrm{T}$ cells, before and after in vitro stimulation with TcAg. The analysis showed significant increase on the percentage of $\mathrm{CD}_{4}^{+} \mathrm{CD} 2 \mathrm{~L}^{-}$cells in CARD patients $(p<0.05)$ in ex vivo analysis as well as non-stimulated cultures when compared with NI and IND

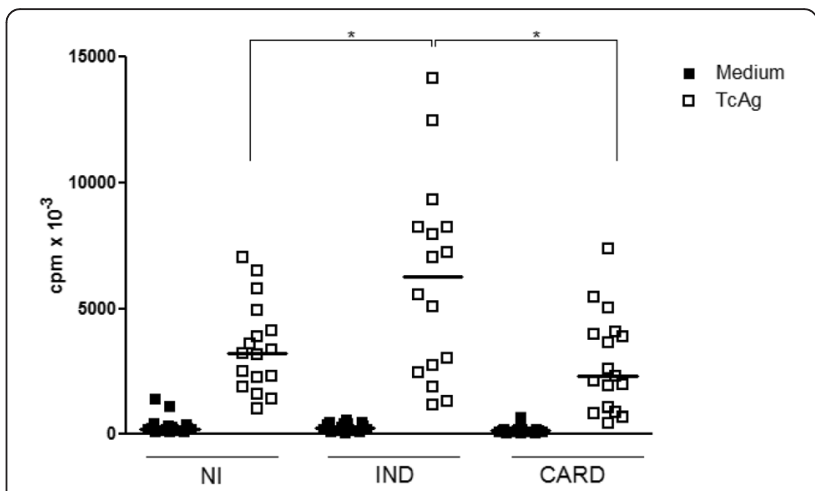

Fig. 1 Proliferation of peripheral blood mononuclear cell induced by T. cruzi antigens (TCAg). A total of $3 \times 10^{5}$ cells/well isolated from non-infected (NI) $(n=15)$, indeterminated (IND) $(n=15)$ and cardiac (CARD) $(n=15)$ groups were cultured in the presence of medium (RPMI-10\% AB serum) and TCAg $(25 \mu \mathrm{g} / \mathrm{mL})$ for 5 days, the last $18 \mathrm{~h}$ in the presence of $0.5 \mu \mathrm{Ci}\left[{ }^{3} \mathrm{H}\right]$-thymidine. The thymidine incorporation was measured by liquid scintillation spectroscopy. Data were reported as means of triplicates of counts per minute (cpm). Significant differences $(p$-value $<0.05)$ in the charts are identified by connecting lines and the symbol (*) for comparisons between the groups. Mann-Whitney test was used for comparison and the results were expressed as the median

groups (Fig. 2a). Moreover, after TcAg in vitro stimulation, a higher percentage of $\mathrm{CD} 4{ }^{+} \mathrm{CD} 62 \mathrm{~L}^{-}$cells in CARD patients $(p<0.05)$ it was also observed when compared to $\mathrm{NI}$ individuals (Fig. 2a). Ex vivo expression of CD62 $\mathrm{L}^{-}$by $\mathrm{CD}^{+}$cells and after in vitro culture in the presence or not of TcAg did not show any statistically significant differences between the study groups (Fig. 2b).

\section{Lymphocytes from IND and CARD patient presented elevated frequency of apoptosis after in vitro TcAg stimulation}

The low proliferative response and high percentage of $\mathrm{CD} 4{ }^{+} \mathrm{CD} 6 \mathrm{~L}^{-} \mathrm{T}$ cells observed in CARD patients might be related to regulatory mechanisms involved in the control of the immune response induced by $T$. cruzi. In this context, apoptosis has been previously demonstrated as play a role in experimental model of acute $T$. cruzi infection [23-26] and also in human heart tissues [27]. In order to investigate if apoptosis might be a factor related to the lower proliferative response and if it is caused by high $\mathrm{T}$ cell activation in the CARD patients, the frequency of annexin $\mathrm{V}^{+}$and active caspase $3^{+}$was analyzed as markers of apoptosis.

Our data show that after in vitro stimulation with TcAg the lymphocytes from CARD displayed high frequency of annexin $\mathrm{V}^{+}$when compared with IND and NI groups (Fig. 3a). The higher frequency of annexin $\mathrm{V}^{+}$in $\mathrm{CD}^{+}{ }^{+} \mathrm{T}$ cells was observed in IND and CARD patients as compared to NI (Fig. $3 \mathrm{~b}$ ). On the other hand, lower frequency of annexin ${ }^{+}$in $\mathrm{CD}^{+} \mathrm{T}$ cells were observed in 

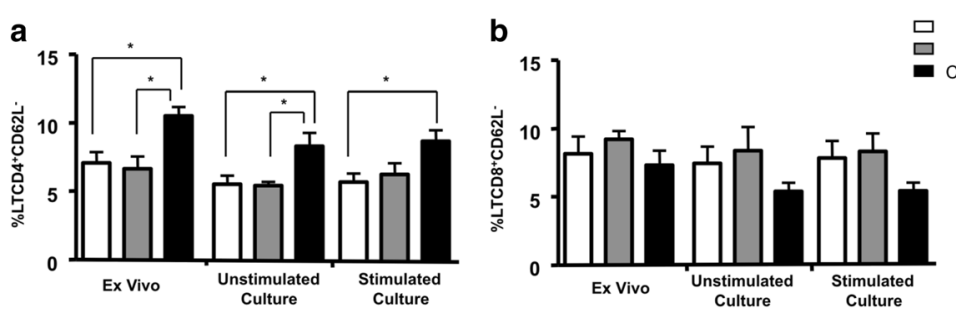

Fig. 2 Analysis of percentage of downregulation of $\mathrm{CD} 62 \mathrm{~L}$ by $C D 4^{+}(\mathbf{a})$ and $\mathrm{CD} 8^{+}(\mathbf{b}) \mathrm{T}$ cell subsets in the peripheral blood from chagasic patients, in ex vivo context and after in vitro stimulation with T. cruzi antigens, from patients with distinct clinical forms of Chagas disease: indeterminate - IND ( $n=9$, gray bars); cardiac - CARD ( $n=14$, black bars) and non-infected individuals - NI ( $n=15$, white bars). The results were expressed as mean \pm standard deviation (SD). Significant differences $(p<0.05)$ in the charts are identified by connecting lines for comparisons between groups

IND and NI groups as compared with CARD group (Fig. 3c). A similar profile was observed for the cultures in the presence of Staurosporin-STP, a positive control for apoptosis.

The frequency of total lymphocytes and $\mathrm{CD} 4^{+}$or $\mathrm{CD}^{+} \mathrm{T}$ cells subsets from IND and CARD patients exhibited similar apoptosis profile as compared with $\mathrm{NI}$ individuals when active caspase $3^{+}$was analyzed (Fig. $3 a$ and b, respectively).

\section{Activated Lymphocytes ${ }^{+}$TNF- $\mathrm{a}^{+}$form CARD patients were susceptible to apoptosis}

A second hypothesis to explain the induction of programmed cell death in lymphocytes from chagasic patients involves the cytokine environment. It is known that TNF$\alpha$ is a major cytokine implicated in the apoptosis pathway. Thus, we have further evaluated serum levels and intracytoplasmic expression of this cytokine ex vivo and following incubation with TcAg. We observed that plasma from
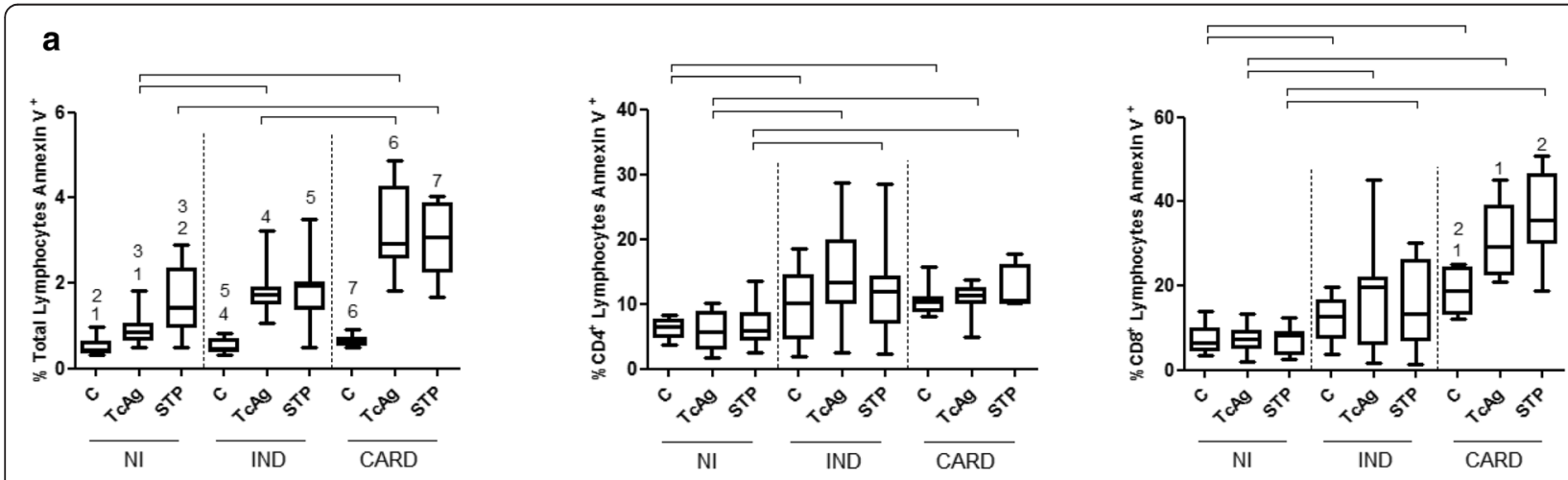

b
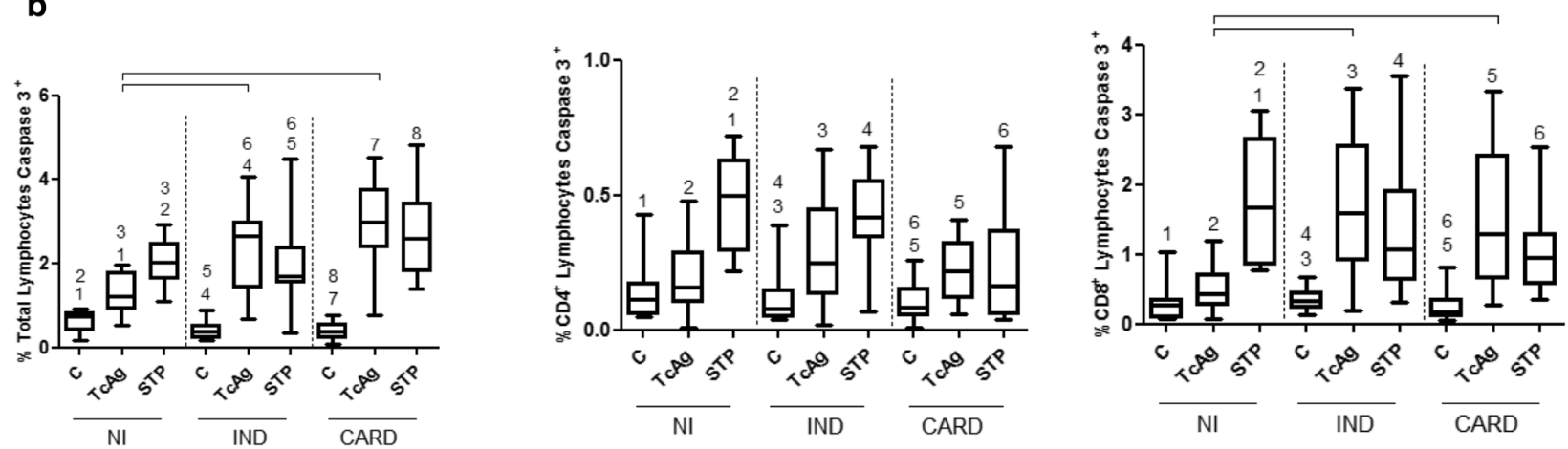

Fig. 3 The apoptotic profile of T lymphocytes from peripheral blood of uninfected individuals (NI) and patients with Chagas disease - indeterminate (IND) or cardiac (CARD) form. The detection of apoptosis was performed using the percentage of annexin ${ }^{+}$(panel a) and caspase $3^{+}$(panel b) in total lymphocytes, $\mathrm{CD}^{+}$or $\mathrm{CD}^{+} \mathrm{T}$ cell subsets. The lymphocytes were evaluated without stimulation - control cultures (C) and after in vitro stimulation with TcAg (T. cruzi antigens) and STP (staurosporin). Mann-Whitney test was used for comparison and the results were expressed as the median with interquartile range. Differences $(p<0.05)$ are presented by the corresponding numbers and connecting lines in the box plot graphs 
CARD patients presented a higher expression of TNF- $\alpha$ than IND and NI groups $(p<0.05)$. Also, after TcAg stimulation, chagasic patients (IND and CARD) presented a higher frequency of TNF- $\alpha$ by total lymphocytes (Fig. 4b), and $\mathrm{CD}^{+}{ }^{+} \mathrm{T}$ or $\mathrm{CD} 8^{+} \mathrm{T}$ cells when compared with NI groups (Fig. 4c and d, respectively). Analysis of serum levels of IFN- $\gamma$ and IL-10 were also performed. IFN- $\gamma$ was elevated in sera from cardiac patients and IL-10 in indeterminate patients as previously shown [28]. In this study we observed that IL-2 was also elevated in sera from cardiac patients (Additional file 1). These results did not show any association with apoptosis.
To determine whether TNF- $\alpha$ expression by total lymphocytes and $\mathrm{CD} 4^{+}$or $\mathrm{CD}^{+} \mathrm{T}$ cells subsets is associated with the frequency of apoptosis, we performed a correlative analysis between the frequency of apoptosis and TNF- $\alpha$ expression. We observed a positive and significant correlation between high frequency of annexin ${ }^{+}$in $\mathrm{CD}^{+}{ }^{+} \mathrm{T}$ cells and high frequency of TNF- $\alpha$ in $\mathrm{CD} 4^{+} \mathrm{T}$ cells both in IND and CARD groups. Moreover, a significant positive correlation was found, between frequency of annexin ${ }^{+} \mathrm{CD}^{+}{ }^{+} \mathrm{T}$ cells and $\mathrm{TNF}-\alpha^{+} \mathrm{CD} 8^{+} \mathrm{T}$ cells in CARD group (Fig. 4d). Together, these results suggested that both $\mathrm{CD}^{+}$and $\mathrm{CD} 8^{+} \mathrm{T}$ cells from CARD patients

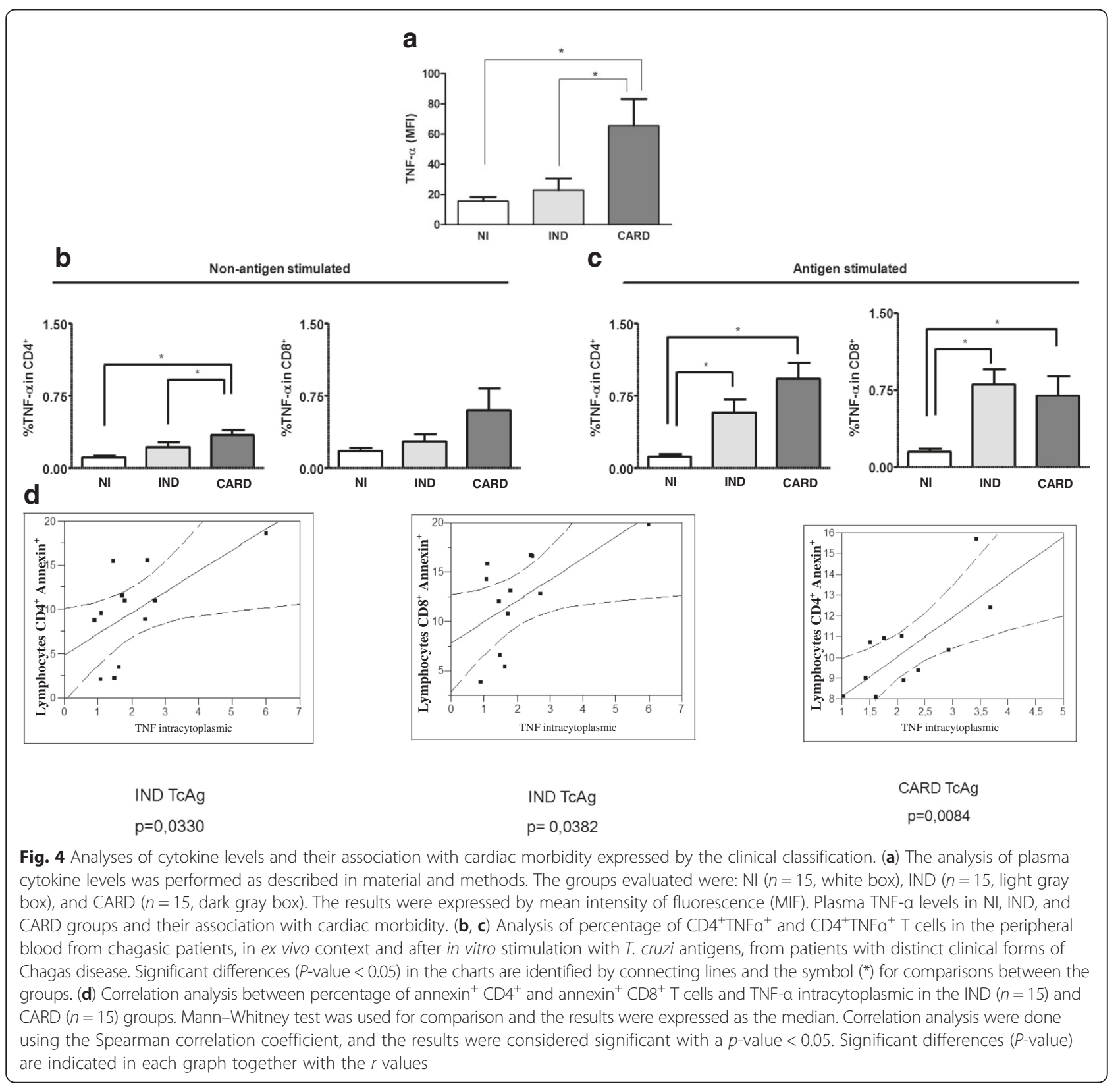


expressing TNF- $\alpha$ were highly susceptible to undergo apoptosis upon in vitro stimulation.

\section{Cell apoptosis in CARD patients might be induced by TNF receptors superfamily and/or caspase family pathway}

Once we showed that CARD patients presented higher frequency of apoptotic cells, the next step was to identify the possible apoptotic pathway used to activate T apoptosis in T cells from patients with this clinical form, before and after in vitro stimulation with TcAg antigen. Initially, 31 apoptosis-related genes from TNF/TNFR superfamily and Caspase family were grouped and categorized according to their respective families and function. Analysis of the others 53 genes of human apoptosis pathway were also performed and these results did not show any significant differences in all groups (data not shown).

In the absence of in vitro TcAg stimulation, when we evaluated the TNF/TNFR superfamily genes from CARD group was determined. The results showed that cell death receptors (FADD, TRADD, TNFRSF10A (TNF receptor superfamily member 10A), TNFRSF10B, TNFRSF11B, TNFRSF21 and TNFRSF25) were up-regulated when compared with IND group (Fig. 5a). Moreover, other proapoptotic genes (FAS, FASL, TNFSF8, TNFRSF9, TRAIL, TRAF2) were also up-regulated in CARD patients when compared with individuals from the IND group (Fig. 5a). When also evaluated the caspase family genes, the results showed that caspase 1 (CASP1), caspase 2 (CASP2), caspase 3 (CASP3), caspase 4 (CASP4), caspase 5 (CASP5), caspase 7 (CASP7), caspase 9 (CASP9), caspase 10 (CASP10) and caspase 14 (CASP14) genes, were upregulated in CARD group in comparison with IND patients (Fig. 5b).

Interestingly, the in vitro TcAg stimulation increased considerably the expression of cell death TNF/TNFR superfamily as well as caspase family receptors genes (FADD, TRADD, TNFRSF10A, TNFRSF10B, TNFRSF11B, TNFRSF21, TNFRSF25, TNFSF10, FAS, FASLG, TNFRSF9, TNFSF8, TRAF2, TRAF4) (Fig. 5c and d, respectively). Furthermore, high expression of genes such as TNFRSF1A, CD27, LTA, TRF3, TRF4 and CASP3 were observed after PBMCs cultures from CARD when compared to IND patients (Fig. 5c and d, respectively). Moreover, the CD70 gene was downregulated in CARD patients when compared to IND patients (Fig. $5 \mathrm{c}$ ).

\section{Discussion}

In the present work, we have shown that apoptosis is associated with reduced proliferative response, a high expression of $\mathrm{T} \mathrm{CD} 4^{+} \mathrm{CD}_{2} 2 \mathrm{~L}^{-}$cells, an increase TNF- $\alpha$ intracellular production and expression of genes of cell death TNF/TNFR superfamily and caspase family in CARD patients.
In this context, some studies have been shown that CARD patients presented low proliferation of $\mathrm{T}$ cells when compared with healthy and non-chagasic cardiomyopathy donors [29-32]. Although, the mechanisms of proliferative dysfunction in Chagas disease need further investigation, studies suggest that they could be related to the decrease of co-stimulatory molecules expression, receptor cytokine starvation or expression of inhibitory receptors as PD-1 [12, 32, 33].

Some studies suggest that activated cells are susceptible to apoptosis, which may represent a mechanism of immunoregulation $[34,35]$. To assess the activation status of $\mathrm{T}$ cell subsets, we evaluated whether CD62L is downregulated in these cell subpopulations. Our data showed that CARD patients presented a significantly higher percentage of $\mathrm{TCD}^{+}{ }^{+} \mathrm{CD} 62 \mathrm{~L}^{-}$cells suggesting that a putative involvement of this cell type in the exacerbation of the immune response to the parasite and, consequently, on the development of myocarditis by cell death induced by activation. Dos Santos et al. [36] showed that the majority of TCD4 and TCD8 lymphocytes in the inflammatory foci from the heart of chagasic patients did not express or slightly expressed CD62L and T CD8 ${ }^{+}$cells are the majority of the activated cells in the tissue when compared with $\mathrm{CD}^{+} \mathrm{T}$ cells. The inflammatory process occurring in Chagas' disease mainly consists of CD8 T lymphocytes, CD4 T lymphocytes and macrophages. The extent of inflammatory reaction and the tissue damage caused may contribute to loss of myocardial cells, and to the heart failure that is observed on more severe cases of chronic Chagas' disease. Tostes Jr et al. [37] showed that myocardial cell loss by apoptosis and fibrosis contributes to heart failure in the chronic phase of Chagas' disease. In fact, apoptosis has been considered a cause of heart failure in other diseases such as myocardial infarction and heart hypertrophy [38, 39], as well as a mechanism involved in the control of the immune response in experimental models [26]. On the other hand, heart failure by itself may induce apoptosis [40].

In this work, high expression of annexin by lymphocytes from CARD group was observed when compared with IND and NI groups, as well as an increase on the expression of annexin by $\mathrm{CD}^{+} \mathrm{T}$ cells and caspase by both $\mathrm{CD}^{+}$and $\mathrm{CD}^{+} \mathrm{T}$ cells by chagasic patients when compared with NI group after in vitro stimulation with T. cruzi antigens. In Chagas' disease, the occurrence of apoptosis in $\mathrm{T}$ lymphocytes was observed after antigen stimulation in experimental models [26] although its significance in terms of clinical form or outcome of the disease was not clear. Apoptosis-like death has been reported in amastigote nests and trypomastigotes forms from T. cruzi, and this mechanism has been associated with control of parasite burden regulated by the parasite itself or by the host, parasite evasion of the host's immune 


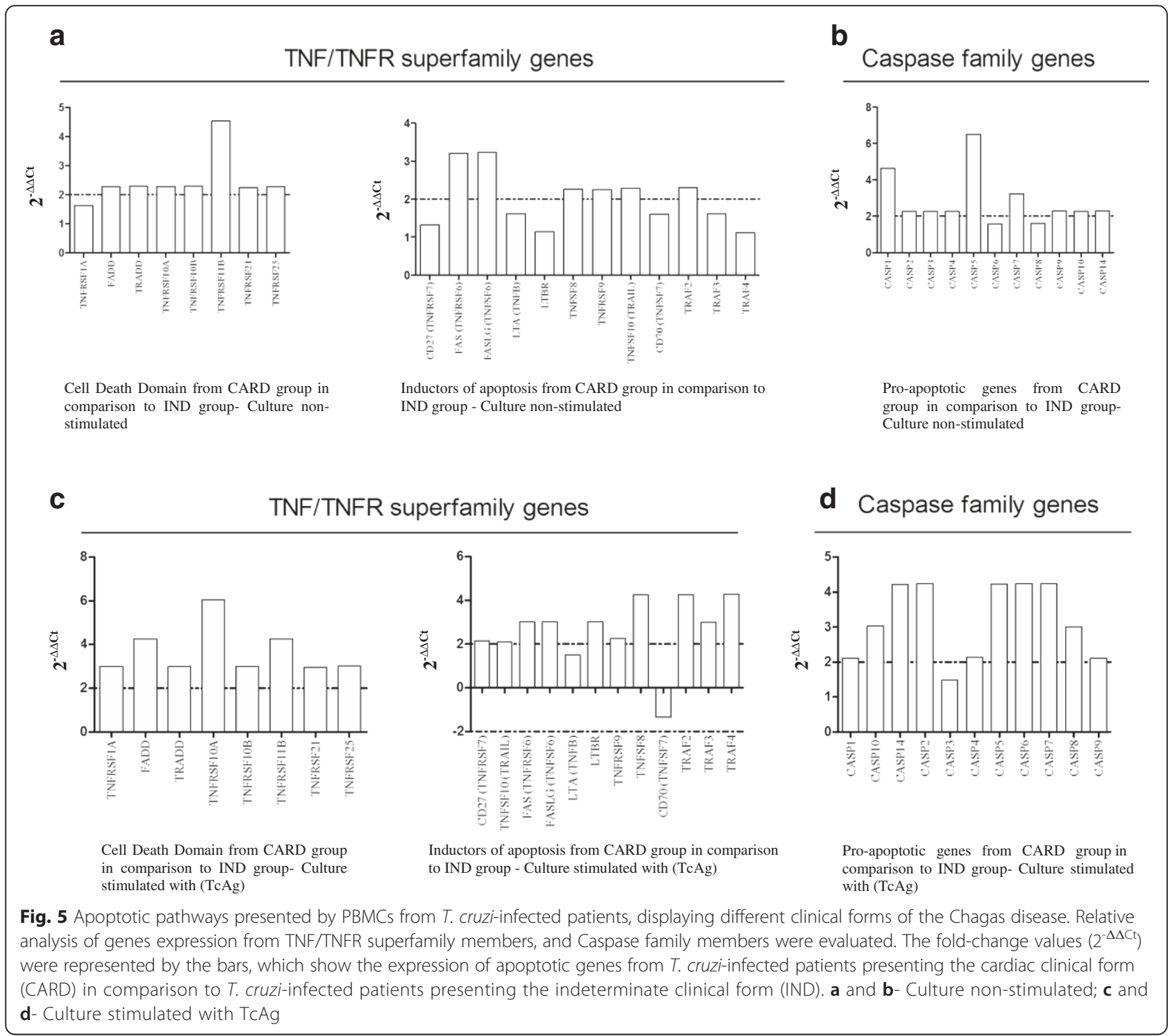

response and clonal selection [41-44]. Together, these findings suggest that although the lymphocytes from CARD patients presented lower proliferative response upon antigenic recall, lymphocytes from IND and CARD patients presented a singular ability to undergo apoptosis that may reflect different regulatory mechanism.

Rodrigues et al. [45] demonstrated a high percentage of lymphocyte apoptosis in patients with a severe cardiomyopathy, associating this event to activation of programmed death pathways, by Fas/Fas-L or TNF- $\alpha$ receptors, leading to parasite escape, and consequently, to a continuous stimulation of the immune system. In this context, $\mathrm{T}$ cells apoptosis in experimental model leads to an increase of parasite growth [46]. Indeed, apoptosis has been suggested to be an important mechanism to control the immune response and heart damages [47].
In order to determine whether TNF- $\alpha$ contributes to $\mathrm{T}$ cell apoptosis, the plasmatic and intracellular production by $T$ cell subsets was evaluated. Our data demonstrated that CARD group showed increased levels of circulating and intracytoplasmic TNF- $\alpha$, and up-regulation of the TNF receptor gene superfamily. Lula et al. [48] have shown correlation among soluble ligands of TNF superfamily (TNF- $\alpha$, TRAIL and FasL/CD95L) and functional disorders of the left ventricle in chronic chagasic patients with cardiomyopathy. These results are associated with ligand receptors associated with programmed cell death, suggesting that apoptotic mechanisms are involved with the development of miocardiopathy in Chagas disease.

Ferreira et al. [49] showed a correlation between high serum levels of TNF- $\alpha$ and the occurrence of severe Chagas cardiomyopathy. Also, it has been shown that 
there is an inverted correlation between high levels of TNF- $\alpha$ with the lowest left ventricular ejection fraction seen in patients with chronic Chagas cardiomyopathy [50]. Moreover, patients with heart failure are shown to have a significantly lower PBMC proliferative response but higher levels of apoptosis and Fas and Fas-L expression [45]. TNF- $\alpha$ may play a role on the high levels apoptosis and in the low proliferative response observed in patients with heart failure. TNF- $\alpha$ may contribute to the induction of apoptosis by the interaction with its receptor or by induction of Fas and Fas-L expression [51]. Our results suggest that the high levels of TNF- $\alpha$ detected in plasma from CARD group may contribute to the heart condition. Additionally, our data support the hypothesis that high levels of TNF- $\alpha$ and up-regulation of the TNF receptor gene superfamily lead to an increase in apoptosis, and consequently the exacerbation of the pathology.

\section{Conclusions}

Here, we showed that apoptosis is associated with low proliferative response, intense $\mathrm{T}$ cell activation, high TNF- $\alpha$ production and up-regulation of genes associated with TNF receptors superfamily and caspase family in CARD 'patients. These results suggest that apoptosis could interfere on the development and/or maintenance of the different clinical forms of Chagas disease. Assuming that the immunological regulation in the IND group, may control the development of Chagas cardiomyopathy, the absence of this mechanism in the CARD group, may be one of the factors associated with sustained inflammation which would, consequently, lead to a higher morbidity in the latter group. The association of lymphocyte apoptosis, induced by the constant activation of the immunological system, with high levels of inflammatory cytokines and associated pathological events (fibrosis and apoptosis) may contribute with the development and progression of heart injuries in the chronic phase of the human Chagas disease.

\section{Additional file}

Additional file 1: Figure S1. Analyses of plasma cytokine levels expressed by the clinical classification. The analysis of plasma levels was performed as described in material and methods. The groups evaluated were: $\mathrm{NI}(n=15$, white box), IND ( $n=15$, light gray box), and CARD ( $n=15$, dark gray box). The results were expressed by mean intensity of fluorescence (MIF). (A) Plasma TNF-a levels in NI, IND, and CARD groups. (B) Plasma IL-2 levels in NI, IND, and CARD groups. (C) Plasma IFN- $\gamma$ levels in NI, IND, and CARD groups. (D) Plasma IL-10 levels in NI, IND, and CARD groups. Significant differences ( $P$-value $<0.05)$. Statistical comparative analyses were performed, in groups of two, between the NI, IND, and CARD groups, using the non-parametric Kruskal-Wallis test and Mann-Whitney $\mathrm{U}$ test, together with the Bonferroni correction (significance level, $0.05 / 3=0.0167$ ). The letters represent statistically significant differences $(p<0.05)$ between the groups: $a$ = difference when compared to NI group; $b=$ difference when compared to IND group; $\mathrm{c}=$ difference when compared to CARD group. (PDF $113 \mathrm{~kb})$

\section{Abbreviations}

CARD: cardiac clinical form of chagas disease; CASP: caspase family genes; DEATH Domain Proteins: FADD, TNFRSF10A, TNFRSF10B (DR5), TNFRSF11B, TNFRSF21, TNFRSF25 (DR3), TRADD; FACS: fluorescence-activated cell sorter: FasL: fas ligand; FITC: fluorescein isothiacynate; HSP70: 70 kilodalton heat shock proteins; IFN-Y: interferon-gamma; IL-10: interleukin 10; IL-2: interleukin 2; IND: indeterminate clinical form of chagas disease; LVDD: left ventricular diastolic diameter; LVEF: left ventricular ejection fraction; mAb: monoclonal antibodies; NI: non-infected; PBMC: peripheral blood mononuclear cells; PCR: polymerase chain reaction; PerCP: peridinin chlorophyll protein complex; PHA: Phytohaemagglutinin; RT: room temperature; RT- gPCR: Relative quantification in real-time-polymerase chain reaction; RT-PCR: reverse transcription-polymerase chain reaction; STP: Staurosporin; TcAg: soluble T. cruzi antigens; TCD4 ${ }^{+}$: helper T cells; TCD8 $^{+}$: cytotoxic T cell; TNF: tumor necrosis factor; TNF/TNFR Domain Proteins: FAS (TNFRSF6), FASLG (TNFSF6), TNFSF10 (TRAIL), TNFRSF10A, TNFRSF10B (DR5), TNFRSF11B, TNFRSF21, TNFRSF25 (DR3), TNFRSF9; TNFR: tumor necrosis factor receptor; TNF-a: tumor necrosis factor alpha; TRAF domain proteins: TRAF2, TRAF4; UFMG: Universidade Federal de Minas Gerais.

\section{Competing interests}

The authors declare that they have no competing interests.

\section{Authors' contributions}

Conception and design of the experiments: ATC, JASG, ACT, EMSF and RCO. Performed the experiments: ATC, JAF, KFS, RCCF, PHGG. Analyzed the data: ATC, JASG, ACT, MJFM, PHGG. Contributed reagents/materials, analysis tools: JASG, RCO, RTF. Wrote the paper: ATC, JASG, JAF, ROC. Assisted with patient care and case identification: MOCR. All authors read and approved the final manuscript.

\section{Acknowledgements}

This work financially supported by Conselho Nacional de Desenvolvimento Científico e Tecnológico (CNPq) (Grant \# 474887/2004-9; Grant \# 404151/ 2012-4; Grant \# 474796/2012-4, Grant \# 470304/2011-1) and Fundação de Amparo Pesquisa do Estado de Minas Gerais (FAPEMIG) (Grant \# CBB-1322/ 05; Grant \# PPM-00501-13); Programa de Apoio à Pesquisa Estratégica em Saúde/FIOCRUZ (PAPES/FIOCRUZ) (PAPES IV - n 400266/2006-7, PAPES $V$ - n ${ }^{\circ}$ Grant\# 407692/2012-6). Ana Thereza Chaves is supported by a doctoral degree fellowship from Coordenação de Aperfeiçoamento de Pessoal de Nível Superior (CAPES) - PROSUP ( $n^{\circ}$ 078/2006-9). Rodrigo Correa-Oliveira, Manoel Otávio da Costa Rocha, Juliana de Assis Silva Gomes Estanislau, Andréa Teixeira Carvalho, Ricardo Toshio Fujiwara and Elaine Maria de Souza Fagundes are supported by CNPq fellowships (Bolsa de produtividade em Pesquisa).

We thank Adriana Bozzi of the Stanford Cardiovascular Institute, Stanford University for comments that greatly improved the manuscript.

\section{Author details}

${ }^{1}$ Laboratório de Imunologia Celular e Molecular, Centro de Pesquisas René Rachou, Fiocruz, Belo Horizonte, Brazil. ${ }^{2}$ Laboratório de Biologia das Interações Celulares, Departamento de Morfologia, Instituto de Ciências Biológicas, UFMG, Belo Horizonte, Brazil. ${ }^{3}$ Programa de Pós graduação em Medicina Tropical e Infectologia, Faculdade de Medicina, UFMG, Belo Horizonte, Brazil. ${ }^{4}$ Laboratório de Biomarcadores de Diagnóstico e Monitoração, Centro de Pesquisas René Rachou, Fiocruz, Belo Horizonte, Brazil. ${ }^{5}$ Laboratório de Imunologia e Genômica de Parasitos, Departamento de Parasitologia, Instituto de Ciências Biológicas, UFMG, Belo Horizonte, Brazil. ${ }^{6}$ Departamento de Fisiologia e Biofísica, Instituto de Ciências Biológicas, UFMG, Belo Horizonte, Brazil. ${ }^{7}$ Instituto Nacional de Ciência e Tecnologia em Doenças Tropicais - INCT-DT, Minas Gerais, Brazil. ${ }^{8}$ NUPEB, Universidade Federal de Ouro Preto, Ouro Preto, Brazil.

Received: 7 March 2015 Accepted: 20 April 2016

Published online: 30 April 2016

\section{References}

1. World Health Organization. Fact sheet 340. Geneva, Switzerland: World Health Organization; 2012. http://www.who.int. Accessed 29 October 2012.

2. Rocha MO, Ribeiro AL, Teixeira MM. Clinical management of chronic Chagas cardiomyopathy. Front Biosci. 2003;8:e44-54. Review.

3. Rocha MO, Teixeira MM, Ribeiro AL. An update on the management of Chagas cardiomyopathy. Expert Rev Anti Infect Ther. 2007;5(4):727-43. Review. 
4. Dias JC. The indeterminate form of human chronic Chagas' disease A clinical epidemiological review. Rev Soc Bras Med Trop. 1989;22(3):147-56. Review.

5. Pereira IR, Vilar-Pereira G, Silva AA, Moreira OC, Britto C, Sarmento ED, LannesVieira J. Tumor necrosis factor is a therapeutic target for immunological unbalance and cardiac abnormalities in chronic experimental Chagas' heart disease. Mediators Inflamm. 2014;2014:798078. doi:10.1155/2014/798078. Epub 2014 Jul 22. PubMed PMID: 25140115, PubMed Central PMCID: PMC4130030.

6. Sousa GR, Gomes JA, Fares RC, Damásio MP, Chaves AT, Ferreira KS, Nunes MC, Medeiros NI, Valente VA, Corrêa-Oliveira R, Rocha MO. Plasma cytokine expression is associated with cardiac morbidity in Chagas disease. PLoS One. 2014;9(3):e87082. doi:10.1371/journal.pone.0087082.eCollection2014. PubMed PMID: 24603474; PubMed Central PMCID: PMC3945957.

7. Gomes JA, Molica AM, Keesen TS, Morato MJ, de Araujo FF, Fares RC, Fiuza JA, Chaves AT, Pinheiro V, Nunes Mdo C, Correa-Oliveira R, da Costa Rocha $\mathrm{MO}$. Inflammatory mediators from monocytes down-regulate cellular proliferation and enhance cytokines production in patients with polar clinical forms of Chagas disease. Hum Immunol. 2014;75(1):20-8. doi:10. 1016/j.humimm.2013.09.009. Epub 2013 Sep 24.

8. Fares RC, Gomes Jde A, Garzoni LR, Waghabi MC, Saraiva RM, Medeiros NI, Oliveira-Prado R, Sangenis LH, Chambela Mda C, de Araújo FF, Teixeira-Carvalho A, Damásio MP, Valente VA, Ferreira KS, Sousa GR, Rocha MO, Correa-Oliveira R. Matrix metalloproteinases 2 and 9 are differentially expressed in patients with indeterminate and cardiac clinical forms of Chagas disease. Infect Immun. 2013; 81(10):3600-8. doi:10.1128/IAl.00153-13. Epub 2013 Jul 15. PubMed PMID: 23856618; PubMed Central PMCID: PMC3811750.

9. Gomes JA, Bahia-Oliveira LM, Rocha MO, Busek SC, Teixeira MM, Silva JS, Correa-Oliveira R. Type 1chemokine receptor expression in Chagas' disease correlates with morbidity in cardiac patients. Infect Immun. 2005;73(12): 7960-6. PubMed PMID: 16299288; PubMed Central PMCID: PMC1307097.

10. Gomes JA, Campi Azevedo AC, Teixeira Carvalho A, Silveira Lemos D, Vitelli Avelar D, Sathler-Avelar R, Peruhype-Magalhães V, Silvestre KF, Batista MA, Schachnik NC, Correa-Oliveira R, Eloi Santos S, Martins-Filho OA. Impaired phagocytic capacity driven by downregulation of major phagocytosisrelated cell surface molecules elicits an overall modulatory cytokine profile in neutrophils and monocytes from the indeterminate clinical form of Chagas disease. Immunobiology. 2012;217(10):1005-16. doi:10.1016/j.imbio. 2012.01.014. Epub2012Jan20.

11. Dutra WO, Menezes CA, Magalhães LM, Gollob KJ. Immunoregulatory networks in human Chagas disease. Parasite Immunol. 2014;36(8):377-87. doi:10.1111/pim.12107. Review. PubMed PMID: 24611805; PubMed Central PMCID: PMC4143493.

12. Dias FC, Medina Tda S, Mendes-Junior CT, Dantas RO, Pissetti CW, Rodrigues Junior V, Dellalibera-Joviliano R, Marin-Neto JA, Gutierrez FR, Moreau P, Silva JS, Donadi EA. Polymorphic sites at the immunoregulatory CTLA-4 gene are associated with chronic chagas disease and its clinical manifestations. PLoS One. 2013;8(10):e78367. doi:10.1371/journal.pone.0078367. PubMed PMID: 24205212, PubMed Central PMCID: PMC3813449, eCollection 2013.

13. de Araújo FF, Corrêa-Oliveira R, Rocha MO, Chaves AT, Fiuza JA, Fares RC, Ferreira KS, Nunes MC, Keesen TS, Damasio MP, Teixeira-Carvalho A, Gomes JA. Foxp $3^{+} \mathrm{CD} 25^{\text {(high) }} \mathrm{CD} 4^{+}$regulatory T cells from indeterminate patients with Chagas disease can suppress the effector cells and cytokines and reveal alteredcorrelations with disease severity. Immunobiology. 2012;217(8): 768-77. doi:10.1016/j.imbio.2012.04.008. Epub 2012 May 9.

14. Esper $L$, Utsch L, Soriani FM, Brant F, Esteves Arantes RM, Campos CF, Pinho V, Souza DG, Teixeira MM, Tanowitz HB, Vieira LQ, Machado FS. Regulatory effects of IL-18 on cytokine profiles and development of myocarditis during Trypanosoma cruzi infection. Microbes Infect. 2014;16(6):481-90. doi:10.1016/ j.micinf.2014.03.007. Epub 2014 Apr 1.

15. Minoprio P, Itohara $S$, Heusser $C$, Tonegawa S, Coutinho A. Immunobiology ofmurine $T$. cruzi infection: the predominance of parasite-nonspecific responses and the activation of TCRI T cells. Immunol Rev. 1989;112:183-207. Review.

16. Welsh RM, McNally JM. Immune deficiency, immune silencing, and clonal exhaustion of T cell responses during viral infections. Curr Opin Microbiol. 1999;2(4):382-7. Review.

17. Longhi SA, Atienza A, Perez Prados G, Buying A, Balouz V, Buscaglia CA, Santos R, Tasso LM, Bonato R, Chiale P, Pinilla C, Judkowski VA, Gómez KA. Cytokine production but lack of proliferation in peripheral blood mononuclear cells from chronic Chagas' disease cardiomyopathy patients in response to T. cruzi ribosomal P proteins. PLoS Negl Trop Dis. 2014;8(6): e2906. doi:10.1371/journal.pntd.0002906.eCollection2014Jun. PubMed PMID: 24901991; PubMed Central PMCID: PMC4046937.
18. Leguizamón MS, Mocetti E, García Rivello H, Argibay P, Campetella O. Trans-sialidase from Trypanosoma cruzi induces apoptosis in cells from the immune system in vivo. J Infect Dis. 1999;180(4):1398-402.

19. Marañón C, Planelles L, Alonso C, López MC. HSP70 from Trypanosoma cruzi is endowed with specific cell proliferation potential leading to apoptosis. Int Immunol. 2000;12(12):1685-93.

20. DosReis GA, Lopes MF. The importance of apoptosis for immune regulation in Chagas disease. Mem Inst Oswaldo Cruz. 2009;104 Suppl 1:259-62.

21. Gomes JA, Bahia-Oliveira LM, Rocha MO, Martins-Filho OA, Gazzinelli G, Correa-Oliveira R. Evidence that development of severe cardiomyopathy in human Chagas' disease is due to a Th1-specific immune response. Infect Immun. 2003;71(3):1185-93. PubMed PMID: 12595431, PubMed Central PMCID: PMC148818.

22. Sambrook J, Gething MJ. Protein structure. Chaperones, paperones. Nature. 1989;342(6247):224-5. PubMed PMID: 2572969

23. DosReis GA, Fonseca ME, Lopes MF. Programmed T-cell death in experimental Chagas disease. Parasitol Today. 1995;11(10):391-4

24. Lopes MF, DosReis GA. Apoptosis as a cause of T-cell unresponsiveness in experimental Chagas' disease. Braz J Med Biol Res. 1995;28(8):913-8. Review.

25. Lopes MF, Cunha JM, Bezerra FL, Gonzalez MS, Gomes JE, Lapa E, Silva JR, Garcia ES, Dos Reis GA. Trypanosoma cruzi: both chemically induced andtriatomine-derived metacyclic trypomastigotes cause the same immunologicaldisturbances in the infected mammalian host. Exp Parasitol. 1995;80(2):194-204.

26. Lopes MF, Da Veiga VF, Santos AR, Fonseca ME, DosReis GA. Activation-induced $\mathrm{CD}^{+} \mathrm{T}$ cell death by apoptosis in experimental Chagas' disease. J Immunol. 1995;154(2):744-52.

27. Rodrigues V Jr, Agrelli GS, Leon SC, Silva Teixeira DN, Tostes S Jr, RochaRodrigues DB. Fas/Fas-L expression, apoptosis and low proliferative response are associated with heart failure in patients with chronic Chagas' disease. Microbes Infect. 2008;10(1):29-37. Epub 2007 Oct 2. PubMed PMID: 18078776.

28. Sousa GR, Gomes JA, Fares RC, Damásio MP, Chaves AT, Ferreira KS, Nunes MC, Medeiros NI, Valente VA, Corrêa-Oliveira R, Rocha MO. Plasma cytokine expression is associated with cardiac morbidity in Chagas disease. PLoS One. 2014;9(3):e87082. doi:10.1371/journal.pone.0087082. PubMed PMID: 24603474, PubMed Central PMCID: PMC3945957, eCollection 2014.

29. Giraldo NA, Bolaños NI, Cuellar A, Roa N, Cucunubá Z, Rosas F, Velasco V, Puerta CJ, González JM. T Iymphocytes from chagasic patients are activated but lack proliferative capacity and down-regulate CD28 and CD3ろ. PLoS Negl Trop Dis. 2013;7(1):e2038. doi:10.1371/journal.pntd. 0002038. PubMed PMID: 23383358, PubMed Central PMCID: PMC3561132, Epub 2013 Jan 31.

30. Kierszenbaum F, Cuna WR, Beltz LA, Sztein MB. Trypanosomal immunosuppressive factor: a secretion product(s) of Trypanosoma cruzi that inhibits proliferation and IL-2 receptor expression by activated human peripheral blood mononuclear cells. J Immunol. 1990;144(10):4000.

31. Mosca W, Briceño L, Hernández Ml. Cell mediated immunity in Chagas' disease. Trypanosoma cruzi antigens induce suppression of the in vitro proliferative response of mononuclear cells. Mem Inst Oswaldo Cruz. 1991; 86(2):147-52.

32. Maleckar JR, Kierszenbaum F. Variations in cell-mediated immunity to Trypanosoma cruzi during experimental Chagas' disease. Ann Trop Med Parasitol. 1983;77(3):247-54.

33. Argüello RJ, Albareda MC, Alvarez MG, Bertocchi G, Armenti AH, Vigliano C, Meckert PC, Tarleton RL, Laucella SA. Inhibitory receptors are expressed by Trypanosoma cruzi-specific effector T cells and in hearts of subjects with chronic Chagas disease. PLoS One. 2012;7(5):e35966. doi:10.1371/journal. pone.0035966. PubMed PMID: 22574131, PubMed Central PMCID: PMC3344843, Epub 2012 May 4.

34. Azuma M, Phillips JH, Lanier LL. CD28- T lymphocytes. Antigenic and functional properties. J Immunol. 1993;150(4):1147-59.

35. Ritprajak P, Azuma M. Intrinsic and extrinsic control of expression of the immunoregulatory molecule PD-L1 in epithelial cells and squamous cell carcinoma. Oral Oncol. 2015;51(3):221-8. doi:10.1016/j.oraloncology. 2014.11.014. Epub 2014 Dec 12. Review.

36. dos Santos PV, Roffê E, Santiago HC, Torres RA, Marino AP, Paiva CN, Silva AA, Gazzinelli RT, Lannes-Vieira J. Prevalence of $C D 8\left({ }^{+}\right)$alpha beta T cells in Trypanosoma cruzi-elicited myocarditis is associated with acquisition of CD62L(Low)LFA-1(High)VLA-4(High) activation phenotype and expression 
of IFN-gamma-inducible adhesion and chemoattractant molecules. Microbes Infect. 2001;3(12):971-84.

37. Tostes Jr S, Bertulucci Rocha-Rodrigues D, de Araujo PG, Rodrigues Jr V. Myocardiocyte apoptosis in heart failure in chronic Chagas' disease. Int J Cardiol. 2005;99(2):233-7.

38. Frustaci A, Kajstura J, Chimenti C, Jakoniuk I, Leri A, Maseri A, Nadal-Ginard B, Anversa P. Myocardial cell death in human diabetes. Circ Res. 2000;87(12): $1123-32$.

39. Feuerstein GZ. Apoptosis in cardiac diseases-new opportunities for novel therapeutics for heart diseases. Cardiovasc Drugs Ther. 1999;13(4):289-94. Review.

40. Olivetti G, Abbi R, Quaini F, Kajstura J, Cheng W, Nitahara JA, Quaini E, Di Loreto C, Beltrami CA, Krajewski S, Reed JC, Anversa P. Apoptosis in the failing human heart. N Engl J Med. 1997;336(16):1131-41.

41. Zhang J, Andrade ZA, Yu ZX, Andrade SG, Takeda K, Sadirgursky M, Ferrans VJ. Apoptosis in a canine model of acute Chagasic myocarditis. J Mol Cell Cardiol. 1999;31(3):581-96.

42. de Souza EM, Araújo-Jorge TC, Bailly C, Lansiaux A, Batista MM, Oliveira GM, Soeiro MN. Host and parasite apoptosis following Trypanosoma cruzi infection in in vitro and in vivo models. Cell Tissue Res. 2003;314(2):223-35. Epub 2003 Aug 20.

43. De Souza EM, Nefertiti AS, Bailly C, Lansiaux A, Soeiro MN. Differential apoptosis-like cell death in amastigote and trypomastigote forms from Trypanosoma cruzi-infected heart cells in vitro. Cell Tissue Res. 2010;341(1): 173-80. doi:10.1007/s00441-010-0985-5. Epub 2010 May 22.

44. Castro-Sesquen YE, Gilman RH, Paico H, Yauri V, Angulo N, Ccopa F, Bern C. Cell death and serum markers of collagen metabolism during cardiac remodeling in Cavia porcellus experimentally infected with Trypanosoma cruzi. PLoS Negl Trop Dis. 2013;7(2):e1996. doi:10.1371/journal.pntd.0001996. PubMed PMID: 23409197, PubMed Central PMCID: PMC3566988, Epub 2013 Feb 7.

45. Rodrigues Jr V, Agrelli GS, Leon SC, Silva Teixeira DN, Tostes Jr S, Rocha-Rodrigues DB. Fas/Fas-L expression, apoptosis and low proliferative response are associated with heart failure in patients with chronic Chagas' disease. Microbes Infect. 2008; 10(1):29-37. Epub 2007 Oct 2.

46. Nunes MP, Andrade RM, Lopes MF, DosReis GA. Activation-induced T cell deathexacerbates Trypanosoma cruzi replication in macrophages cocultured with CD4+ T lymphocytes from infected hosts. J Immunol. 1998;160(3):1313-9.

47. Henriques Pons A, Oliveira GM, Paiva MM, Correa AF, Batista MM, Bisaggio RC, Liu CC, Cotta-De-Almeida V, Coutinho CM, Persechini PM, Araujo-Jorge TC. Evidence for a perforin-mediated mechanism controlling cardiac inflammation in Trypanosoma cruzi infection. Int J Exp Pathol. 2002;83(2): 67-79. PubMed PMID: 12084043; PubMed Central PMCID: PMC2517672.

48. Lula JF, Rocha MO, Nunes Mdo C, Ribeiro AL, Teixeira MM, Bahia MT, Talvani A. Plasma concentrations of tumour necrosis factor-alpha, tumour necrosis factor-related apoptosis-inducing ligand, and FasLigand/CD95L in patients with Chagas cardiomyopathy correlate with left ventricular dysfunction. Eur J Heart Fail. 2009:11(9):825-31. doi:10.1093/eurihf/hfp105. Epub 2009 Aug 4.

49. Ferreira RC, lanni BM, Abel LC, Buck P, Mady C, Kalil J, Cunha-Neto E. Increased plasma levels of tumor necrosis factor-alpha in asymptomatic/ "indeterminate" and Chagas disease cardiomyopathy patients. Mem Inst Oswaldo Cruz. 2003:98(3):407-11. Epub 2003 Jul 18.

50. Talvani A, Rocha MO, Barcelos LS, Gomes YM, Ribeiro AL, Teixeira MM. Elevated concentrations of CCL2 and tumor necrosis factor-alpha in chagasic cardiomyopathy. Clin Infect Dis. 2004;38(7):943-50. Epub 2004 Mar 10. PubMed PMID: 15034825.

51. Elzey BD, Griffith TS, Herndon JM, Barreiro R, Tschopp J, Ferguson TA. Regulation of Fas ligand-induced apoptosis by TNF. J Immunol. 2001;167(6):3049-56.

\section{Submit your next manuscript to BioMed Central and we will help you at every step:}

- We accept pre-submission inquiries

- Our selector tool helps you to find the most relevant journal

- We provide round the clock customer support

- Convenient online submission

- Thorough peer review

- Inclusion in PubMed and all major indexing services

- Maximum visibility for your research

Submit your manuscript at www.biomedcentral.com/submit

C) Biomed Central 